sulphuric and nitric acid are added. Glycerine has an affinity for water. A molecule of water is abstracted, and a molecule of nitrous acid takes its place. Nitro-glycerine may be put into the fire or it may be struck without any dangerous consequence. If however it be set on fire by a fulminant, there is an explosion. If, as stated, the Russian bombs were made of glass, there must have been small projections made in the glass shell when manufactured, filled with fulminating powder. The explosive character arises from this: Nitrogen is composed of molecules in pairs of atoms. Nitric acid contains only ope atom in its molecules. Upon this atom being set free from its unstable combination in the glycerine, the two atoms of nitrogen rush together, producing a vast amount of energy of combination in the shape of heat. The gaseous products are thus heated, and an explosion takes place immediately."

A School of Gardening and Practical Floriculture has been established at the Crystal Palace, under the superintendence of Mr. Edward Milner.

M. Daudigny, electrical engineer in Paris, has sent to the Municipal Council a petition asking for authority to establish on the top of the Colonne de Juillet a large electric lamp fed by a magneto-electric machine of fifty horse-power. This enormous light is to be diffused by a large reflector of special construction.

A MOST successful experiment in theatre illumination was tried on March 30 and $3 \mathbf{I}$, at the Athenæum of the rue des Martyrs, Paris, with the Werdermann incandescent light. The peculiarity of it is that it can be graduated at will for scenic effects, either by introducing resistance coils or varying the velocity of the Gramme machine. These experiments were witnessed by several influential members of the Municipal Council, who on the following morning proposed an inquiry into the propriety of obliging all the theatrical managers to light their halls with electricity.

Mr. F. W. Putnam sends us a paper on Pueblo Pottery, which he contributed to the February number of the American Art Revierv. There are some well-executed coloured illustrations of specimens of the pottery which show some little taste in colour and ornamentation.

$\mathrm{WE}$ have had several replies to our inquiry concerning the late Dr. Thomas Dick's astronomical instruments. They seem to have been disposed of after his death, and only one small instrument can be definitely traced. None of the instruments seem to have been of much scientific value.

MR. Johnston-LAvis writes, under date March 29 :"Vesuvius is to-night again active, lava running down the northwestern slope of the cone. Only the reflection is visible from Naples. On Sunday morning a slight shock, or more correctly subterranean thunder, was felt at Casamicciola, although those in the ruins at the moment only became aware of it by the palor of others present, whose whole attention is arrested by the faintest move or noise."

A Science Students' Association has been formed in Liverpool, which includes all departments of science in its programme; the president is Mr. A. Norman Tate.

THE system of compressed-air clocks, of the use and construction of which in Paris we gave an account some time ago, is likely to have a trial in London. A Bill has been introduced into Parliament for this purpose. The number of stations proposed for the metrofolis is ten.

IN the notice of the meting of the Mathematical Society in Nature, vol. xxiii. p. 379, Mr. Wooster Woodruff Beman's name was misspelt Benson.

Lievt.-Col. H. Collett, of Meean Meer, North-West Punjab, has sent us a money-order for $3 l$. towards the John Duncan Fund. We also acknowledgereceipt of 1 . from M. G. S.
THE additions to the Zoological Society's Gardens during the past week include a Two-Spotted Paradoxure (Nandinia binotata) from West Africa, presented by Mr. A. Wentworth Forbes; a Golden Sparrow (Auripasser euchlorus) from Abyssinia, presented by Mr. J. Abrahams; a Chukar Partridge (Caccabis chukar), a Grey Francolin (Francolinus ponticerianus) from India, presented by M. J. M. Cornely, C.M.Z.S. ; two Indian Antelopes (Antelope cervicapra $\delta$ o) from India, deposited; two Ethiopian Wart Hogs (Phacocharus ethiopicus of \&) from South-East Africa, a Dusky Parrot (Pionus violaceus) from Guiana, three Ceylonese Hanging Parrakeets (Loriculus asiaticus of o \&) from Ceylon, a Yellow Troupial (Xanthosoma flavus) from Buenos Ayres, purchased; a Fork-tailed Jungle Fowl (Gallus furcatus $\delta$ ) from Java, on approval; two Four-horned Antelopes (Tetraceros quadricornis of \&), a Burrhel Wild Sheep (Ovis burrhel \&) from India, a Javan Adjutant (Leptoptilus javanicus) from Java, a Rock-hopper Penguin (Eudyptes chrysocome) from the Falkland Islands, received in exchange.

\section{OUR ASTRONOMICAL COLUMN}

The Variable Stars U Cephei and U Grminorum.We learn from Mr. Knott that Ceraski's short-period variable in Cepheus was at a minimum on March 29 at about $12 \mathrm{~h} .45 \mathrm{~m}$. G.M.T.; clouds prevented observations till IIh. $35 \mathrm{~m}$., when it had barely fallen to minimum; for two hours, $11 \mathrm{~h} .45 \mathrm{~m}$. - I 3 h. $45 \mathrm{~m}$., the star's light was sensibly constant-about $9{ }^{\circ} 4 \mathrm{~m}$. On April $3 \mathrm{Mr}$. Knott again obtained a pretty complete observation; the time of minimum, taking the middle of the phase, was $12 \mathrm{~h} .24 \mathrm{~m}$. G.M.T.; for nearly $2 \mathrm{~h}$. $30 \mathrm{~m}$., or from $\mathrm{IIh}$. Iom. to $13 \mathrm{~h} .36 \mathrm{~m}$., the star remained about $94 \mathrm{~m}$. Guided by these and previous observations the following approximate times of minima are inferred, and it is to be hoped that the series may be well observed :-

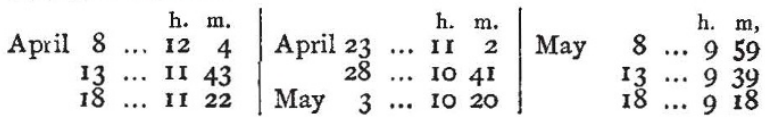

This variable has been hitherto called $\mathrm{T}$ Cephei in this column, but Mr. Knott draws attention to the circumstance that Ceraski (Astron. Nach., No. 2343) applied that designation last October to another variable discovered by him, the position of which by meridian observations at Moscow was found to be in R.A. 2 Ih. 7m. 57.05s., Decl. $+68^{\circ} \mathrm{o}^{\prime} 8^{\prime \prime} \cdot 4$ for $1880^{\circ} \mathrm{O}$, and we accordingly follow his suggestion that the short-period variable will be more properly termed U Cephei.

$\mathrm{U}$ Geminorum was observed by Mr. Knott at about the maximum, or about 9'3 m., on April 2 and 3. Maxima of this very irregular variable star are by no means easy to catch. It precedes the principal component of $\Sigma_{\mathrm{I}} \mathrm{I}_{5} 8 \mathrm{by} \mathrm{Im}, 26 \cdot 5 \mathrm{~s}$, and is north of it $7^{\prime} 31^{\prime \prime}$. Prof. Winnecke gave a series of comparison stars in Astron. Nach., No. I 120. Argelander's position for 1855 is R.A. 7 h. $46 \mathrm{~m}$. $29^{\circ} 88 \mathrm{~s}$. ; Decl. $+22^{\circ} 22^{\prime} 4 \mathrm{I}^{\prime \prime} \cdot 5$.

While writing upon variable stars we may mention that B.A.C. 4767 is probably to be included among them. It was estimated $4 \mathrm{~m}$. by D'Agelet on May 15, 1783; it is called $6 \mathrm{~m}$. by Lacaille, Lalande, and Piazzi, and was so estimated in Argelander's Zone, No. 301 ; but although rated $5 \%$ in the Uranometria Argentina it is not found in Heis's Atlas nor in the Uranometria of Argelander, Its place for the present year is in R.A. 14 h. $18 \mathrm{~m}$. $1 \mathrm{~s}$, , with south declination, $24^{\circ} 15^{\prime} \cdot 6$.

The CoMeT of 1812.-Several years since, Mr. W. E. Plummer of the University Observatory, Oxford, after a new reduction of the observations made at Paris and Viviers, which we possess in their original form, found the period of revolution about $I_{2}^{2}$ years less than that given by Encke, so that it is quite possible that the comet may arrive again at perihelion within the present year. We have already mentioned that $M$. Schulhof of Paris is engaged upon a strict investigation of the elements of this comet, and has the intention of preparing extended ephemerides, in the same manner that he has done for several of the minor planets which had not been observed at several oppositions, but the sweeping lines for every fourth day throughout the year are given in Herr Mahn's ephemeris computed on the suggestion of Prof. Winnecke, which will be found in the Vierteljahrsschrift der Astronomischen Gesellschaft, 12 Jahrgang. 